\title{
ANSERJ
}

Vol. 12, No. 1

Spring / printemps 2021

pp. $38-57$

Canadian Journal of Nonprofit and Social Economy Research

Revue canadienne de recherche sur les OSBL et l'économie sociale

\section{Pathways to Local Partnerships in a Semi-Rural Setting: A Qualitative Study of Community Engagement and Employer- Supported Volunteering in Small and Medium Enterprises and Local Nonprofits}

\author{
Myriam Gagnon, Myriam Beaudry, \& Louise Lemyre \\ University of Ottawa \\ Alexandra Guay-Charette \\ Concordia University
}

\begin{abstract}
There remains a knowledge gap regarding the factors that drive the development of business-nonprofit partnerships in the context of employer-supported volunteering-especially in small and medium enterprises. Furthermore, there is a need to consider how enterprises operate in their cultural contexts to better understand how they support volunteering trends in Canada. This study aimed to improve understanding of the multi-level factors that foster the development of business-nonprofit partnerships in the context of employer-supported volunteering. Fifteen semi-structured interviews were conducted with community and small business actors in a semi-rural setting in Francophone Québec. Results challenged the traditional view of volunteer support as a distinct activity, showing an integrated system of inter-dependence. Results suggest the relevance of conceptualizing small enterprises' support of volunteering as part of an inclusive approach to community engagement.

\section{RÉSUMÉ}

Les facteurs liés au développement de partenariats entre entreprises et OBNL dans le contexte du bénévolat appuyé par l'employeur sont méconnus - particulièrement au sein des petites et moyennes entreprises. II est également pertinent de considérer le contexte culturel pour mieux comprendre les tendances canadiennes du bénévolat appuyé par l'employeur. Cette étude vise l'obtention d'une meilleure compréhension des facteurs multiniveaux associés au développement de partenariats entreprises-OBNL dans le contexte du soutien au bénévolat. Quinze entretiens semistructurés ont été effectués auprès d'acteurs du secteur communautaire et des petites entreprises dans un milieu semi-rural francophone-québécois. Les résultats repositionnent la notion d'activités distinctes et témoignent plutôt d'un système intégré d'interdépendances. Les résultats suggèrent de conceptualiser le soutien au bénévolat des petites entreprises au sein d'une approche inclusive d'engagement communautaire.
\end{abstract}

Keywords / Mots clés: Employer-supported volunteering; SME; Business-nonprofit partnerships; Community engagement / Bénévolat appuyé par l'employeur; PME; Partenariats entreprises-OBNL; Engagement communautaire 


\section{Gagnon, Beaudry, Lemyre, \& Guay-Charette (2021)}

\section{INTRODUCTION}

Employer-supported volunteering (ESV), which encompasses strategies used by employers to promote and facilitate their employees' involvement in the community, has become portrayed as an opportunity to mobilize human resources for community well-being. For example, in a recent Canadian study, full-time employees who reported the presence of employer support for volunteering were significantly more likely to get involved in informal volunteering, financial donating, and in-kind donating, while controlling for a combination of socio-demographic variables (Gagnon \& Lemyre, 2020). Types of ESV include time-based support, financial support, logistical support, recognition of employees' volunteering involvement, and advertising volunteering opportunities (Rodell, Breitsohl, Schröder, \& Keating, 2015). ESV is often undertaken in cooperation with nonprofit organizations (Lorenz, Gentile, \& Wehner, 2011). However, understanding of business-nonprofit partnership dynamics is limited.

ESV literature has focused heavily on the employee-employer dyad and the perspective of large corporations (Cook \& Burchell, 2018), often at the individual level. Thus, there is a lack of integration of the perspective of other key stakeholders involved in ESV (e.g., nonprofits), as well as a lack of integration of contextual factors at play in ESV dynamics (e.g., organizational practices, community context), especially in small enterprises and communities. There is a need to improve understanding of the factors that contribute to both the development of successful business-nonprofit partnerships and to positive outcomes for the community in the context of ESV (Austin, 2000; Austin \& Seitanidi, 2012a, 2012b; Cho \& Kelly, 2014). The current study aimed to address this need by exploring multi-level factors associated with the development of partnerships between small and medium enterprises (SMEs) and nonprofits, and the related community outcomes in a semi-rural setting in Francophone Québec.

\section{THE CASE OF SMALL AND MEDIUM ENTERPRISES}

In Canada, few studies distinguish between SMEs and large businesses when reporting on ESV activities and related organizational practices (Basil, Runte, Basil, \& Usher, 2011). However, research suggests that SMEs may experience community involvement, ESV, and business-nonprofit partnerships differently than large organizations do. SMEs have their own particular set of challenges for the implementation of community involvement activities, including limited financial resources, tools, support services, and infrastructure (Kechiche \& Soparnot, 2012). Therefore, SME community involvement tends to favour in-kind contributions in products, services, or competencies (Madden, Scaife, \& Crissman, 2006), while large businesses favour financial initiatives, such as donations and sponsoring (Russo \& Tencati, 2009).

Overall, SMEs tend to adopt informal and implicit corporate social responsibility (CSR) strategies, while large businesses use more formal procedures, such as environmental and human resources policies (Baumann-Pauly, Wickert, Spence, \& Scherer, 2013; Russo \& Tencati, 2009). In the context of ESV, SMEs have been shown to be less likely than large businesses to engage in strategic planning targeting specific causes and more likely to adopt an informal approach (Basil, Runte, Basil, \& Usher, 2011). While large businesses place considerable emphasis on the external reporting of CSR, SMEs devote little effort to external communication about their activities (Baumann-Paul et al., 2013). Consequently, due to the informal nature of CSR in SMEs, nonprofits may be less aware of SMEs' community involvement practices, which could hinder business-nonprofit partnerships. Indeed, a study of the corporate community involvement practices of American SMEs found that representatives expressed interest in establishing more sustainable, mutually beneficial partnerships with nonprofits, but they perceived a lack of requests for support or interest from nonprofits (Zatepilina-Monacell, 2015). Moreover, little is known about the specific manifestations of ESV within SMEs, or how different stakeholder groups (e.g., employees, employers, nonprofit representatives) perceive and understand it. Given this gap and the important distinctions between SMEs and large businesses, a better understanding of ESV in SMEs and the dynamics involved in the development of SME-nonprofit partnerships in the context of community involvement is required. 


\section{Gagnon, Beaudry, Lemyre, \& Guay-Charette (2021)}

\section{UNDERSTANDING THE FRANCOPHONE QUÉBEC CONTEXT FROM A SOCIAL- ECOLOGICAL PERSPECTIVE}

In the Canadian context, Francophone Québec requires special consideration due to the particularities of community involvement patterns. Data from Canada-wide surveys on community engagement trends and practices has repeatedly shown significantly lower rates of formal involvement (e.g., formal volunteering) in Québec compared with other provinces (Curtis, Baer, Grabb, \& Perks, 2003; Turcotte, 2015; Vézina \& Crompton, 2012). These differences may be explained by cultural and socio-historical hypotheses. Some scholars have suggested that Quebeckers prefer informal methods of civic engagement (Laforest, 2011); others have suggested that the role of longstanding Catholic and religious influences combined with the influence of the relatively large welfare state may have contributed to the perception of a relatively low need for voluntary engagement (Gaudet \& Reed, 2004; Hwang, Andersen, \& Grabb, 2007; Runte, Basil, \& Runte, 2010). Québec's lower rates of involvement also appear to extend to the context of ESV (Hurst, 2012; Runte, Basil, \& Runte, 2010). Cross-cultural comparison studies on ESV comparing Québec and other provinces are sparse. In their survey study on ESV, Mary Runte, Debra Basil, \& Robert Runte (2010) found that Québec companies were slightly more likely than non-Québec companies to focus on the external benefits of ESV, such as community perception, rather than internal benefits, such as increased employee satisfaction and commitment. This highlights the relevance of considering factors pertaining to the broader social environment (e.g., cultural factors) in order to better understand the dynamics at play in ESV. In addition, examining ESV dynamics in Francophone Québec fosters a better understanding of ESV practices in SMEs, which provide 87.4 percent of jobs in Québec. Small businesses (99 employees or less) account for 97.9 percent of businesses in Québec (Industry Canada, 2019).

Urie Bronfenbrenner's (1977) social-ecological model highlights the role that the social environment can play in ESV dynamics. The model posits that individuals and their behaviours are nested within broader systems in their social environment (e.g., family, employer, community, economy, society), which they influence and are influenced by. Although the ecological systems theory has been used to understand the antecedents and responses to formal volunteering (Kulik, 2007a, 2007b), little attention has been given to this model in the context of ESV.

In line with a social-ecological approach, this article proposes that in addition to individual-level factors-including the experiences of stakeholders from both sectors-mutually influential ecological systems impact the development and success of business-nonprofit partnerships within Francophone Québec and shape SME-nonprofit partnerships and ESV practices. At the organizational level, this includes the role and characteristics of SMEs in Francophone Québec's business landscape in relation to community engagement (e.g., organizational processes and practices). At the community level, it includes neighbourhood characteristics (e.g., rural, urban, etc.).

\section{NEIGHBOURHOOD CONTEXT AND THE RURAL ADVANTAGE}

Urban and rural settings exhibit different characteristics. In rural and semi-rural regions, for example, residents are more likely to know and trust their neighbours and to have a strong sense of belonging within their community (Turcotte, 2005). These characteristics may contribute to higher engagement, since volunteering is more prevalent in rural regions, as observed in Canadian-wide surveys of participatory behaviour (Reed \& Selbee, 2001; Turcotte, 2005; Vézina \& Crompton, 2012). However, little is known about specificities and dynamics of rural businesses in the context of ESV. Given the higher volunteering rates found in rural settings, examining the development of SME-nonprofit partnerships in smaller communities may provide insight on factors associated with SME community involvement.

\section{PURPOSE OF THE STUDY}

This study aimed to get a better understanding of both the factors involved in the development of SME-nonprofit partner- 


\section{Gagnon, Beaudry, Lemyre, \& Guay-Charette (2021)}

ships within a small community context and the related community implications in order to identify promising practices. As such, the study was guided by three research questions:

1. What is the participant's understanding of ESV in SMEs?

2. What are the barriers and facilitators of SME-nonprofit partnerships in a small community context?

3. What are the perceived outcomes linked to SME-nonprofit partnerships in the context of ESV within a small community setting?

The study was conducted in partnership with the Fédération des centres d'action bénévole du Québec (FCABQ); it is part of a larger interdisciplinary university-community research project with the University of Ottawa titled $E=M^{2}$ (Engagement=Mobilizing Communities and Collaboration).

\section{METHODOLOGY}

In this study, a qualitative methodology based on key informant interviews was employed to gather rich data on perceptions, practices, and influential factors associated with rural ESV and SME-nonprofit partnerships. The research setting was identified through consultation with community partners.

This study examines the case of a semi-rural municipality recognized for its history of successful SME-nonprofit partnership development in the context of ESV; the study of successful (rather than unsuccessful) partnerships was privileged given the lack of previous data on this issue. The regional county municipality is located between two important urban centres in the province of Québec. Population size was estimated at around 40,000 residents (with a density of 34 residents per square kilometre). The average individual income was inferior to the provincial average ( $\$ 22,242$ versus $\$ 25,646)$, and the median age was higher than that of Québec (45.2 years versus 41.5 years; Institut de la statistique du Québec, 2014. Recruitment was facilitated by a community partner (the director of a local volunteer centre) who helped identify key informants from both the business and nonprofit sectors, as per a purposeful sampling strategy (Creswell, 2007). The aim was to recruit stakeholders with different roles in SME-nonprofit partnerships who could provide different insights (e.g., employees and community volunteers may comment primarily on individual factors at play, whereas employers and nonprofit staff may offer a more organizational perspective). The sample comprised 15 participants (eight women and seven men) from four categories: SME employers (owners or managers; $N=3$ ), SME employees $(N=2)$, community organization employees (i.e., local nonprofit coordinators; $N=3$ ), and community volunteers $(N=7)$. Two participating SMEs were from the retail sector and one was from the financial services sector. Some participants in the community volunteer category also discussed instances of experiencing ESV as employees. Characteristics of participating SMEs are presented in Table 1.

Table 1. Overview of participating small and medium enterprises

\begin{tabular}{|c|c|c|c|}
\hline & SME A & SME B & SME C \\
\hline Sector & Retail & Retail & Financial services \\
\hline Number of employees & 47 & 63 & 100 \\
\hline
\end{tabular}

\section{Procedure}

The research team developed the interview guide based on study goals, in consultation with community partners. The interview guide covered the following themes: a) types of employer support for volunteering; b) reasons for involvement; c) perceived ESV and SME community engagement outcomes; and d) facilitators and barriers to SME community engagement and SME-nonprofit partnership development. Fourteen interviews were conducted in person and one was 


\section{Gagnon, Beaudry, Lemyre, \& Guay-Charette (2021)}

conducted by phone. In-person interviews were conducted in French and were held at participants' preferred location. Interviews with community volunteers and SME employees took place at the volunteer centre, while interviews with nonprofit representatives and SME employers were conducted in a private room at their workplace. Interviews lasted from 38 to 128 minutes; they were audio-recorded and transcribed verbatim. Quotes have been translated by the first author.

\section{Analysis}

Data were analyzed by the first three authors using a combination of deductive and inductive analyses (Miles, Huberman, \& Saldaña, 2013) and the NVivo qualitative analysis software. The researchers first developed an a priori coding grid based on study questions and previous ESV research. Six interview transcripts were coded based on this first coding grid, each researcher supplementing the initial coding scheme as new themes emerged from the data. To verify the level of agreement on the codes generated, the three researchers met to compare codes, clarify definitions, and combine emergent codes into an updated coding grid. The researchers then revised the previously coded transcripts and coded the remaining ones. Once all transcripts had been coded, the list of codes was refined to synthesize findings in a smaller number of distinct categories (Thomas, 2006).

\section{FINDINGS}

To investigate multi-level factors involved in SME-nonprofit partnership development in the context of ESV, analyses explored four dimensions of participants' perspectives: a) their conceptualization of ESV, b) challenges and barriers to SMEnonprofit partnerships, c) facilitators and opportunities for SME-nonprofit partnerships, and d) perceived multi-level outcomes of SME-nonprofit partnerships in the context of ESV.

\section{Understanding employer-supported volunteering in the context of small and medium enterprises}

A first important observation was that most respondents did not relate to the term "employer-supported volunteering." SME employers did not describe the different ways in which they supported or facilitated their employees' volunteering as a distinct form of community engagement. Rather, they considered these practices as part of the broader array of community-serving activities performed by their business. This suggests that support for employee involvement was woven into the overall community engagement approach of the business:

Well, since I'm offering them [local nonprofit organization] products for the day, the tent and all that, I may as well check among the entire staff and the management team to see if there's one or more people who want to go to this event [fundraiser] to give out gifts to people, give out juices during the day. (Participant 1, employer, SME A)

\section{Flexible approach}

Strategies commonly cited to support employees' community involvement denoted flexibility, support, and approval on the part of SMEs. These strategies were used in the context of employer-led initiatives, joint employee-employer initiatives, and employees' personal volunteering endeavours. Several participants mentioned flexible work schedules as key to accommodating volunteering endeavours: "Every first Wednesday of the month, she always has her meeting [at a community organization where she volunteers]. So for sure we will never schedule her on Wednesday evening" (Participant 1, employer, SME A). Other commonly reported strategies included employers reducing the barriers to employee engagement via measures such as in-kind incentives (e.g., providing a meal during the activity) and logistical support: "We really took care of everything for them [employees partaking in a fundraising activity for a local nonprofit]. We had made a schedule. We had cleared their agendas. So it went well" (Participant 3, employer, SME C).

\section{Diversity of employer-supported volunteering forms}

Participants reported that SMEs' involvement with the local community took many forms, including in-kind donations, 


\section{Gagnon, Beaudry, Lemyre, \& Guay-Charette (2021)}

lending equipment for community events, and participation in fundraisers for local causes or organizations. Strategies used to promote or facilitate employees' involvement in these activities were vastly informal. The employer from the medium-sized business studied (SME C) reported that her business had a policy on community engagement and activities explicitly focused on fostering employee volunteering. However, none of the SMEs in the study had a formalized approach to or dedicated policy for ESV. Many forms of ESV were described, but the most cited practice was expressing gratitude for employees' involvement. This took place through different means, ranging from implicit approval and verbal thanks to more concrete and formal gestures, such as recognizing an employee's contribution in internal communication tools. SMEs had a tendency to support local, known community organizations through their community engagement practices.

\section{Barriers and obstacles to small and medium enterprise-nonprofit partnership development in the context of employer-supported volunteering}

Participants identified several individual-, organizational-, and community-level factors that could hinder the development of SME-nonprofit partnerships in the context of ESV initiatives.

\section{Individual-level barriers}

The main individual-level barrier to SME-nonprofit partnerships identified by SME employees and employers was a lack of awareness of involvement opportunities. Some cited a lack of knowledge about nonprofits and opportunities for involvement in their community, which could limit the identification of potential interorganizational synergies.

\section{Organizational-level barriers}

In terms of barriers at the organizational level, participants noted that SME-nonprofit partnerships could be hindered by intersectoral distrust, conflicting processes and practices between the two sectors, and difficulties in measuring the impacts of initiatives.

\section{Climate of intersectoral distrust}

Respondents noted that intersectoral mistrust was an important challenge to the development of ties between SMEs and nonprofits. Some respondents mentioned that certain nonprofit representatives were quite resistant to the idea of seeking partnerships with businesses and held a generally negative view of the business sector. This could stem from suspicion regarding businesses' intentions for participating in community involvement and the fear that they may exploit these opportunities for marketing purposes. For their part, SME employers reported that past interactions with nonprofits that appeared disorganized or half-hearted negatively impacted their desire to collaborate. A nonprofit representative reported witnessing caution on the part of businesses being solicited for financial donations, reflecting potential trustbuilding challenges:

But entrepreneurs are heavily solicited. They are cautious. And I understand them. You know, they don't say yes right away. They ask questions: so, what will you do with that money? Often, it's like you want this, but what will you do with it? You ask for a sponsorship, but who will it go to? They ask questions. (Participant 6, nonprofit)

\section{Conflicting processes and practices}

SME employers and nonprofit representatives both mentioned instances where members of the other sector had behaved in a way that did not match their expectations. For example, an employer mentioned having received a support request from a nonprofit via email. Because this was not the employer's preferred mode of communication (the employer preferred the telephone) and made the exchange feel "impersonal," it lowered their interest in establishing a collaboration. Conflicting behaviours and expectations could stem from misunderstandings or a perceived lack of transparency, and they could hinder the desire of both nonprofit representatives and SME employers to embark in a partnership. 


\section{Gagnon, Beaudry, Lemyre, \& Guay-Charette (2021)}

\section{Difficulties measuring the impact of employer-supported volunteering initiatives}

Some SME employers noted that assessing ESV outcomes can be challenging, especially at the organizational and community levels. This could limit the perceived added value of partnering with nonprofits. They reported relying on their "felt" impressions to capture the impact of ESV initiatives: "Well, it's very difficult to talk about impact because it's things, it's feelings there" (Participant 7, nonprofit, former SME employer).

\section{Community-level barriers}

At the community level, SME employers and community representatives identified that neighbourhood and local community characteristics, such as the socio-economic context, could limit SME-nonprofit partnerships. For example, participants mentioned that the financial resources available within their semi-rural community could limit the scope and visibility of community events, thus limiting collaboration opportunities: "We're not a rich place, okay? Everyone has limited means. So when you want to organize something, it's hard to organize something that will stand out, okay?" (Participant 7, nonprofit, former SME employer)

Figure 1 presents barriers and obstacles to the development of SME-nonprofit partnerships.

Figure 1. Barriers to the Development of SME-Nonprofit Partnerships in ESV Initiatives.

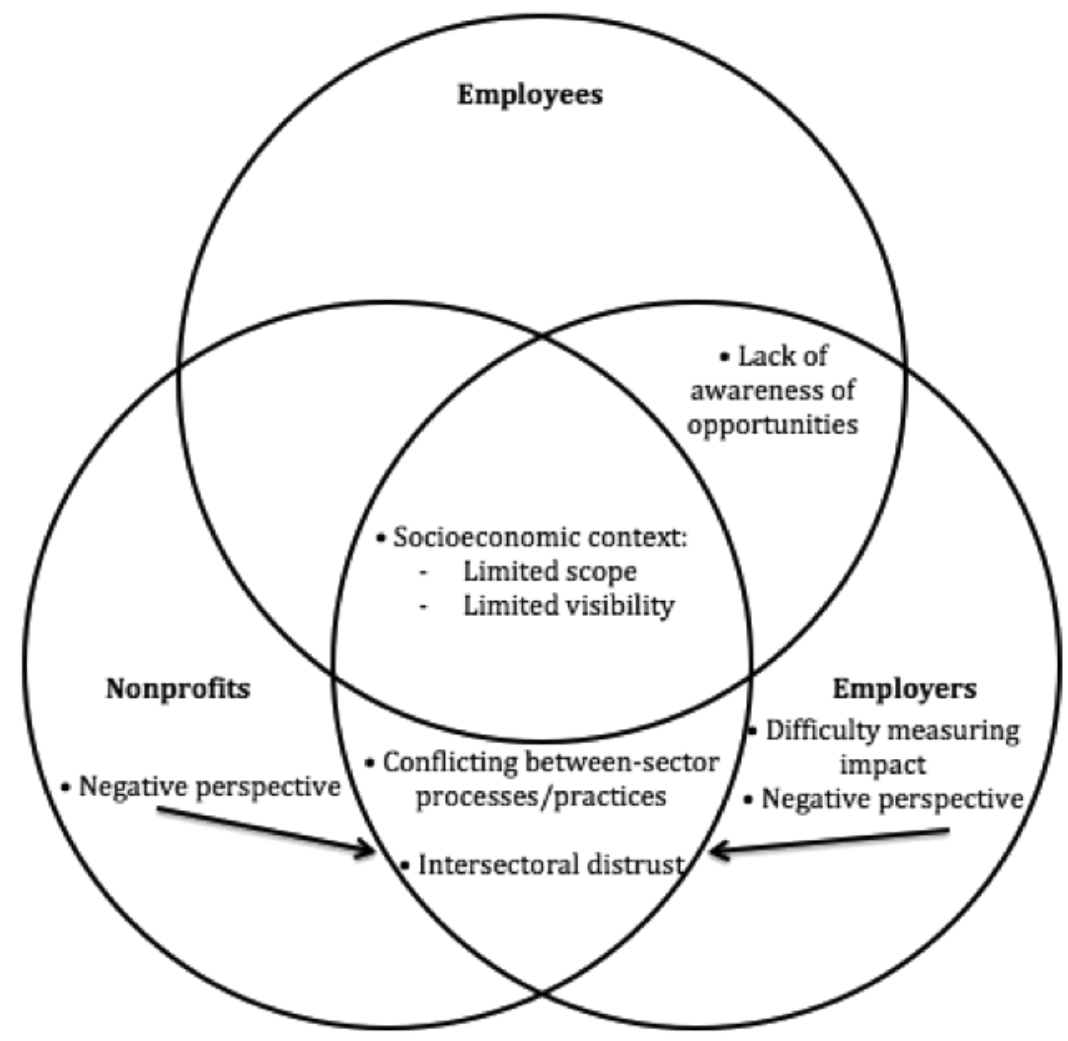

\section{FACILITATORS AND OPPORTUNITIES FOR THE DEVELOPMENT OF SMALL AND MEDIUM ENTERPRISE-NONPROFIT PARTNERSHIPS IN THE CONTEXT OF EMPLOYER-SUPPORTED VOLUNTEERING}

Participants identified several individual-, organizational-, and community-level facilitators for the development of SMEnonprofit partnerships in the context of ESV. 


\section{Gagnon, Beaudry, Lemyre, \& Guay-Charette (2021)}

\section{Individual-level facilitators}

At the individual level, participants mentioned how a sense of belonging and a connection to the local community could facilitate SME-nonprofit partnerships.

\section{Community attachment}

Community attachment and caring emerged as an important theme among both SME and nonprofit representatives. This manifested first through an awareness of interdependencies between sectors. Participants described how both sectors need to work together to ensure the long-term well-being and sustainability of their community. Nonprofit representatives generally perceived local business representatives as actively involved in the community, as illustrated by this quote:

We can't go one without the other here in [our municipality], precisely because there are not a lot of businesses, there is not a large population. And everyone needs to work together to keep [the municipality] alive. So it goes without saying that we work together. Merchants will often participate in all kinds of organizations for the benefit of the population. (Participant 7, nonprofit)

Another manifestation of community attachment involved affective commitments to specific causes or local nonprofit organizations. For SME employers, the desire to give back and contribute to local community development fuelled an openness to supporting and collaborating with nonprofits:

It's evident that to date, the volunteer centre is my hobbyhorse, and it's ... Mr. [X, volunteer centre director] who transmitted his passion to me. [The employees], they are passionate people who are there to help people.

I tip my hat to them at 150 percent. (Participant 1, employer, SME A)

The affective commitment of SME employers was deemed particularly relevant to the development of SME-nonprofit partnerships, as many participants considered that employers and owner-managers largely led or facilitated the community engagement activities.

\section{Organizational-level facilitators}

Participants identified organizational practices that were associated with the development and continuity of SME-nonprofit partnerships. These included the affirmation of organizational strengths, the recognition of the contributions of cross-sectoral partners, the multiplication of intersectoral interactions (cross-pollination), and the formulation of clear objectives.

\section{Affirming organizational strengths}

The ability of nonprofits to position their added value and unique expertise appeared to facilitate SME-nonprofit ties. Participants from all categories described the successful efforts of the local volunteer centre to increase its visibility among the local community, including the business community, by having a representative attend various events and openly communicate its mission, activities, and accomplishments. The volunteer centre director was described as particularly skillful at demonstrating through various channels their organization's unique expertise to the local community and the business sector (e.g., providing training on active listening skills):

[They] position themselves very well in relation to the business community, and they really position their organization as a player, an integral part of community development. (Participant 2, employer, SME B)

Efforts deployed by a nonprofit representative to affirm their organization's strengths contributed to its positive reputation as open, transparent, and valuable within the local business community.

\section{Recognizing and valuing contribution}

Participants also mentioned the importance of recognizing and valuing contributions to strengthen SME-nonprofit relationships. Both SME and nonprofit representatives recognized the important role played by members of the other sector 


\section{Gagnon, Beaudry, Lemyre, \& Guay-Charette (2021)}

in local community development and the success of community engagement activities (such as ESV). Explicitly communicating this appreciation was also highlighted as an important relationship-building behaviour. For example, the volunteer centre's director reported that local entrepreneurs had previously expressed that the simple act of acknowledging their support with a thank-you letter helped set the centre apart and promoted sustainable partnerships. As a subtle yet important feature, it was phrased as expressing gratitude rather than celebrating the performance of an individual or entity. The focus appeared to be on the impact:

But one of the things we do that they notice too, l've always been inclined to do it, [is send thank-you letters]. "You're one of the rare organizations who send us thank you letters" [they say]. That recognition there, I think we're nurturing ties. (Participant 6, nonprofit)

\section{Cross-pollination}

Nonprofit representatives reported fruitful examples speaking to the importance of multiplying inter-sector interactions in order to establish ties between nonprofits and SMEs. This was achieved by facilitating introductions to members of the other sector. For example, the volunteer centre director reported seeking to connect members of their staff to the staff of local enterprises. Moreover, they noted that developing multiple connections between nonprofit staff members and SME employees allowed for the natural unfolding of individual affinities and informal complicity between organizations:

Like with [Business A], [Mr. Smith'] dives right in at 100 miles an hour, you know? But with [Business B], it's [Ms. Jones ${ }^{1}$ ]. People connect with others too. That's important as well.... They share tasks and they often go according to affinities. (Participant 6, nonprofit)

\section{Formulating clear objectives}

Nonprofit representatives discussed the importance of being "clear with [SME representatives] on what we are asking of them" (Participant 6, nonprofit) from the outset in order to facilitate the development of partnerships. This allowed SME representatives to understand the nonprofit's needs and the expectations regarding their role and the scope of their involvement.

\section{Community-level facilitators}

At the community level, facilitators included the existence of spaces fostering SME-nonprofit interactions and the visibility of ESV initiatives.

\section{Intersectoral interaction spaces}

Participants described community characteristics that allowed for the creation of spaces and opportunities for members of the local business and nonprofit sectors to interact in both informal and formal ways.

One pathway to the development of SME-nonprofit partnerships via intersectoral interactions was through familiarity between members of the business and nonprofit sectors. It was attributed to the small size of the community and often facilitated through word of mouth. SME employers noted a preference to get involved with locally based nonprofits that they were familiar with, saying that their existing social networks had sometimes contributed to the establishment of new partnerships via informal introductions. For example, the owner-manager of SME A reported having been introduced to the volunteer centre director by another local business owner. This encounter had led them to organize fundraising activities for the volunteer centre and they encouraged their employees to participate. 


\section{Gagnon, Beaudry, Lemyre, \& Guay-Charette (2021)}

The three SMEs that participated in the study were involved in activities to support the local volunteer centre, with some activities involving employee volunteering (e.g., the preparation of goods for fundraising sales, paid volunteer time). In addition to partnering with the volunteer centre, the employer from SME B reported that their business was involved with a finite number of nonprofits, all of which they had pre-existing ties to. As for formal intersectoral interaction spaces, respondents described the role some organizations played in connecting actors from both sectors and publicly recognizing their contributions to community development. The local Chamber of Commerce, for example, was consistently open to collaborating with nonprofits and acknowledging their contributions to local community development. Indeed, respondents reported that the Chamber of Commerce had begun publicly recognizing local actors for significant contributions to the regional municipal county's development:

Often we'll pay tribute to someone who's done something to improve the region. It's not necessarily growing their business ... [it is] businesspeople who've helped in the community sector. (Participant 7, nonprofit) At the time of data collection, the volunteer centre's director had recently been awarded this distinction for his role in providing services to the community, which further enhanced the volunteer centre's visibility among businesses and within the larger community.

\section{The visibility of nonprofits and employer-supported volunteering initiatives}

Respondents identified that local media outlets played a role in raising awareness about local nonprofits and community initiatives: "You don't go two weeks without hearing about the volunteer centre in the paper, on the community TV channel, on the radio" (Participant 6, nonprofit). Due to SME representatives' preference to get involved with familiar local nonprofits, this appeared to facilitate the development of SME-nonprofit partnerships by contributing to leveraging and legitimizing specific community organizations and causes within the community.

Figure 2 presents facilitators and opportunities for the development of SME-nonprofit partnerships.

Figure 2. Facilitators to the Development of SME-Nonprofit Partnerships in ESV Initiatives.

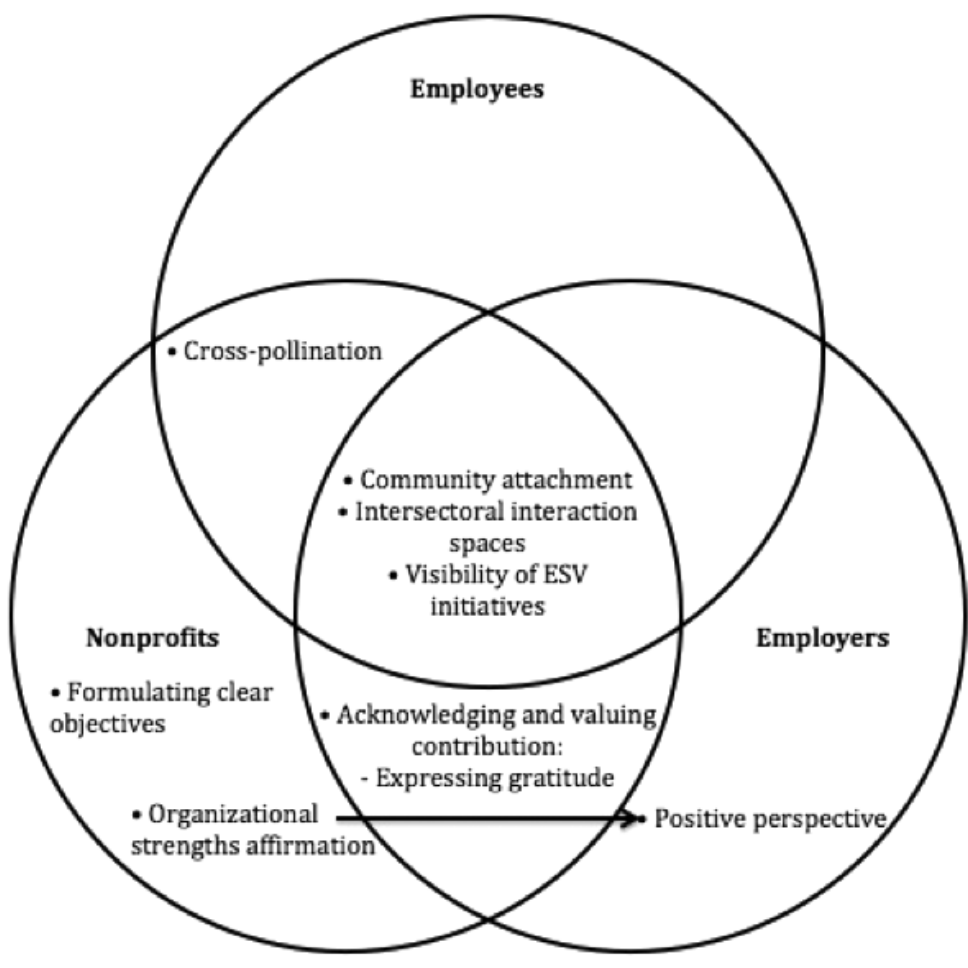




\section{Gagnon, Beaudry, Lemyre, \& Guay-Charette (2021)}

The perceived outcomes of employer-supported volunteering in small and medium enterprises

Participants perceived that successful SME-nonprofit partnerships created in the context of ESV contributed to outcomes for nonprofits, SMEs, and the local community.

\section{Outcomes for nonprofits}

SME employees reported that their ESV experiences increased their awareness of nonprofits' services and activities as well as opportunities for further involvement. This may contribute to increasing the number of volunteers for nonprofits. Indeed, an employer observed that an ESV activity organized with the local volunteer centre had mobilized some employees who had not previously volunteered. Moreover, they recalled that ESV experiences had encouraged some of their employees to continue volunteering on their own.

Not everyone ... incorporated volunteering in their personal life. And I know there are a few who continued to do it after, who got involved. I think there is a financial advisor from here who did income tax returns, who helped people, who gave his time in that way. There are people who helped at the reception. So it was an interesting experience, I think, for people of the [volunteer centre] but for people from [our business] as well. (Participant 3, employer, SME C)

Some participants from other respondent categories (SME employees, community volunteers) confirmed this observation. For example, a retired employee who volunteered at the local volunteer centre mentioned that participating in an ESV activity while they were still in the workforce had initiated their desire to volunteer with the elderly. However, ESV was not always perceived as a lever for increased volunteer involvement. One employee perceived their current level of volunteer involvement, which was facilitated by their employer, as sufficient.

Nonprofit representatives reported that as employers and employees became familiar with their organization, they sometimes became sources of additional support and advocacy by undertaking activities such as promoting the organization and its services within the community, providing financial contributions, and helping to raise money:

They say ... send some of your members, some employees and volunteers and they'll hand out leaflets to promote the service ... they allow us to promote our services and organization without doing too much because "no, no, our employees will do that. We will have a draw and we're the ones who are paying for it." (Participant 6 , nonprofit)

Thus, nonprofit representatives felt that SME employee involvement facilitated by ESV contributed to improving their organization's visibility in the community.

Outcomes for small and medium enterprises

Participants discussed both individual- and organizational-level outcomes for SMEs. At the individual level, employees identified psychological benefits associated with ESV. They expressed deriving enjoyment and gratification from participating in ESV activities. They also perceived that their involvement fostered the development of empathy and open-mindedness, which were sometimes seen as having a positive spillover effect into their work:

It probably brought me closer to the human side [of my profession]. It allows [me] to better understand people's reluctance and difficulties, to better understand their environment ... probably primarily when it comes to work but probably also in my personal life. I probably listen more, and I'm probably more attentive. (Participant 5 , employee, SME B)

Employees also described perceived outcomes linked to organizational commitment. They reported that seeing their employer actively invest time in community causes fostered their organizational pride and enhanced a sense of good "person-organization fit," whereby their employer's values align with their own. Employers also reported finding their involvement 


\section{Gagnon, Beaudry, Lemyre, \& Guay-Charette (2021)}

gratifying. In addition, some employers noted that organizing and participating in ESV initiatives could enhance their social capital by developing their personal social networks, which could lead to opportunities for business development.

At the organizational level, an important theme that emerged from the perspectives of employees and employers alike was ESV's contribution to the reputation of a business. According to employers, the local clientele acknowledged and expressed gratitude toward SMEs' involvement in the community. One employer reported receiving feedback from customers who chose to support their business due to their involvement with the volunteer centre, illustrating that ESV can have direct financial benefits. The other employers believed that consumer choices are based on a wide array of factors that may or may not include SME community engagement. Accordingly, they did not perceive a substantial financial impact from their involvement with ESV. Employers did find that improved reputation due to community involvement could facilitate employee recruitment and retention, and customer retention.

A second organizational outcome encompassed the perceived benefits of ESV activities on the work climate through strengthened relationships among employees and with their employers. Indeed, employees and employers found that ESV activities enabled them to get to know each other on a more personal level. This promoted a sense of cohesion and social support, an outcome sometimes communicated to nonprofit representatives:

I once had a comment from an employer who said [ESV] had improved relationships in his business.... He said ... now everyone speaks to each other ... they have some pride now. They don't just come to punch in and weld anymore, you know. There is something else. (Participant 8 , nonprofit)

Outcomes for the local community

Nonprofit representatives and employers identified certain types of employer-supported initiatives (e.g., fundraising activities) as contributing to community development in several quantifiable ways. For example, an employer reported that the money collected within their business had contributed to the purchase of specific items that benefited the local community in concrete, observable ways:

We helped purchase a vehicle for the distribution of Meals on Wheels. Or sometimes it'll be for the economic development of a community. In [the municipality], we paid for an outdoor pool. So it brings new residents, it brings economic development, it brings community development. So yes, impacts are very concrete. We see them on the field there, a lot. (Participant 3, employer, SME C)

Nonprofit representatives and employees believed that ESV involvement fostered an increased awareness of community needs and services among SME employees and employers. A volunteer reported that participating in a group volunteering activity at the local volunteer centre had increased their awareness and their colleagues' awareness of community needs and of the volunteer centre's contributions- "it made us realize that yes, there is a real need"-as well as the volunteer centre itself: "there are some people who didn't know about [volunteer centre X]" (Participant 15, community volunteer, former employee of SME C).

In turn, nonprofit representatives reported that this increased awareness allowed employee volunteers to refer people they knew (e.g., acquaintances or family members) to community services because they gained greater awareness of their existence. This was thought to increase nonprofit organizations' ability to serve their community. The volunteer centre director described this phenomenon as "naturally occurring referral networks":

People tell us they didn't know this person could have this service ... we call this naturally occurring referral networks. And here, we've often had, for example, a woman calling and saying, my daughter who told me to call you because I could have volunteer transportation or Meals on Wheels. (Participant 6, nonprofit)

Finally, participants described how ESV contributed to strengthening community relationships in three different domains: a) within SMEs, b) between SME and nonprofit representatives, and c) between SME representatives and members of 


\section{Gagnon, Beaudry, Lemyre, \& Guay-Charette (2021)}

the local community. In relation to the second domain, both employers and nonprofit representatives reported that ESV allowed them to establish lasting intersectoral partnerships. The volunteer involvement of SME employees also allowed nonprofit representatives to get to know employees from their local community.

In relation to the third domain (enhanced relationships between SME representatives and members of the local community), participants indicated that participating in ESV activities in the community allowed them to interact with their clientele in a different context and helped develop trusting relationships (e.g., getting to know them on a first-name basis, learning about their personal challenges). An employee reported that this improved relationship helped develop SME representatives' ability to better serve and respond to individualized client needs.

Figure 3 presents a summary of the perceived multi-level outcomes of ESV.

Figure 3. Perceived Multi-Level Outcomes of Employer-Supported Volunteering

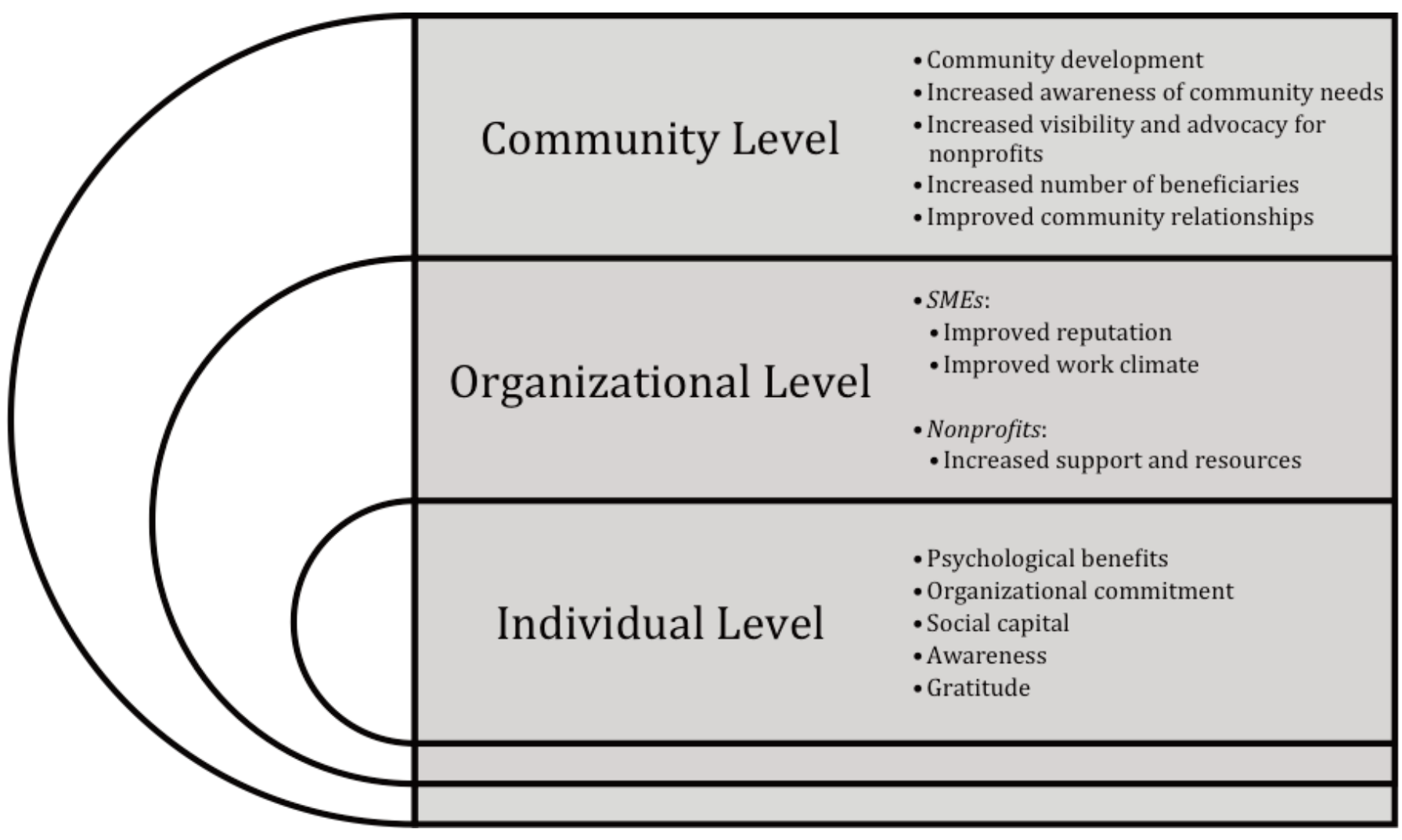

\section{DISCUSSION}

This study documents how ESV manifests within the context of SMEs in a semi-rural municipality of Francophone Québec. It sheds light on multi-level facilitators and barriers to SME-nonprofit partnership development, thus making it possible to identify promising practices for the expansion of joint ESV initiatives. The results also reveal perceived community benefits, which highlights the role of these partnerships in local community vitality.

Employer-supported volunteering: An organic process stemming from community engagement practices This study documents how SMEs regarded the concept of ESV. The results suggest that participants did not particularly 


\section{Gagnon, Beaudry, Lemyre, \& Guay-Charette (2021)}

identify with the ESV vocabulary used in the context of large businesses. Rather, they called for a perspective shift to consider employee participation as embedded within a broader approach to community engagement rather than as a distinct activity. ESV was characterized by diversity (i.e., employees were involved in a variety of activities) and flexibility (i.e., employers showed support and approval by seeking to reduce the barriers to involvement in different ways). These findings contrasted with the formalized understanding of ESV primarily found in the literature (Allen, Galiano, \& Hayes, 2011; Caligiuri, Mencin, \& Jiang, 2013; Gatignon-Turnau \& Mignonac, 2015; Muthuri, Matten, \& Moon, 2009; Peloza \& Hassay, 2006) or in governmental initiatives (Ontario, 2019). Moreover, these results suggest that in order to understand community engagement trends, it is important to identify and use vocabulary that is compatible with the cultural context. Although further research and comparative studies are needed, the vocabulary currently used to collect data on ESV may fail to adequately capture the reality of SMEs in Francophone Québec.

\section{The role of nonprofits in community vitality}

Research on ESV has largely omitted the perspective of nonprofits. Scholars have raised concerns about the challenges faced by nonprofits due to power imbalances (Berger, Cunningham, \& Drumwright, 2004) and suggested that the perceived benefits of ESV for nonprofits may be more about potential than reality (Samuel, Wolf, \& Schilling, 2013). By incorporating the perspective of SME employees and employers as well as community actors (e.g., nonprofit employees and volunteers), this study identified circumstances that foster the development of successful SME-nonprofit partnerships and mutually beneficial outcomes. This supports a win-win-win scenario, as proposed in the literature (Caligiuri, Mencing, \& Jiang, 2013). The study documented the active role nonprofits can play as partnership instigators. This contrasts with findings from the corporate volunteering literature, which finds large businesses to be the main initiators (Samuel, Wolf, \& Schilling, 2013). In this study, various nonprofit practices (formulating clear objectives, affirming organizational strengths, cross-pollination, acknowledging and valuing the contribution of local businesses) were found to help develop and sustain partnerships with local SMEs. These practices appeared to foster the development of mutually beneficial partnerships, as opposed to more traditional philanthropic or "patronizing" partnerships in which businesses take on the role of providers and nonprofits are viewed as dependent recipients (Austin, 2000; Austin \& Seitanidi, 2012a, 2012b; Cho \& Kelly, 2014; Jamali \& Keshishian, 2009). Indeed, initiating partnerships with SMEs appeared to position nonprofit representatives advantageously and enable them to demonstrate their expertise relative to local community needs and specific skills. This contributed to the creation of both "mission-related collaborations" (supporting nonprofits' core activities and target audience) and "marketing collaborations" (advertising and promoting local nonprofits) with local SMEs, as per the typology of business-nonprofit collaborations presented by Ruth Schiller and Micahl Almog-Bar (2013).

\section{Visibility and mutual benefits}

Numerous studies and reports by community organizations have focused on the identification of benefits in the workplace (Volunteer Canada, 2014) associated with ESV. In contrast, this study underscores the importance of enhancing the visibility of the nonprofit initiatives and activities that businesses are contributing to and their community impact. This appeared to help build the case for the role and relevance of business-nonprofit partnerships.

In this study, the volunteer centre's ability to extend its visibility beyond beneficiaries to reach and mobilize members of the business community emerged as a benefit. This appeared to be facilitated by three levels of factors: a) individuallevel factors (e.g., the volunteer centre director's passion for local community issues); b) organizational-level factors and practices (e.g., efforts to enhance the volunteer centre's visibility and publicly showcase its strengths alongside recognition of the business sector's role in community development); and c) contextual factors (e.g., mechanisms in place to recognize both sectors' contributions to community development at the Chamber of Commerce and local media involvement in promoting community initiatives and organizations). Combined, these multi-level factors fostered positive perceptions of the nonprofit sector among the business sector and provided opportunities for SME-nonprofit interactions. Concurrently, it 


\section{Gagnon, Beaudry, Lemyre, \& Guay-Charette (2021)}

challenged mistrust between the two sectors, which emerged as one of the main barriers to intersectoral partnerships. A social-ecological perspective offered a more comprehensive understanding of the interplay of these multi-level factors, their role in the development of SME-nonprofit partnerships, and their resulting social capital, which is defined as "connections among individuals - social networks and the norms of reciprocity and trustworthiness that arise from them" (Putnam, 2000, p. 19). The results suggest that research on ESV can benefit from systemic analysis that considers the influence of broader contextual factors. Future research may consider using systemic frameworks to further analyze ESV partnership dynamics. Elinor Ostrom's $(1990,2005)$ Institutional Analysis and Development Framework could be relevant, as it can be used to improve conceptualizations of inter-organizational collaboration (Amsler \& O'Leary, 2017).

\section{Recognition of impact and in-kind}

Previous research and documentation on ESV has primarily focused on the individual aspects of recognition. The resulting recommendations include a call for businesses to incentivize participation and reward individuals who contribute the most hours to a cause (Boccalandro, 2009). An important contribution of this study was to provide a different outlook on the role of recognition, one that emphasizes impact at the community rather than the individual level. This appeared to stem from cultural factors and rural community characteristics (e.g., caring for the local community and seeing community engagement as a means to help keep the community alive). In the context of interdisciplinary collaboration, reciprocal knowledge affirmation, which can be defined as "the mutual recognition by team members that they respect, value and affirm each other's expertise identity" (MacPhail, Roloff, \& Edmondson, 2009, p. 328), moderates the relationship between expertise, diversity, and collaboration. The results show that in the context of ESV, the process of identifying and validating the expertise of members of the other sector and their contribution to community development (e.g., within the Chamber of Commerce and through letters of thanks sent to SME partners) appeared to foster mutually positive perspectives. It helped provide a sense of meaning to their involvement, which is an important driver of volunteering (Rodell, 2013). Moreover, the identification and acknowledgement of concrete contributions to local community development (e.g., the purchase of a vehicle for Meals on Wheels) highlighted community outcomes from SME engagement, thus promoting their participation. Therefore, while individual recognition and incentive measures may promote involvement to a certain extent, this study shows the importance of acknowledging community impact and contribution. This calls for a shift from recognizing highly engaged individual volunteers (e.g., through certificates of accomplishment) to better identifying and communicating local community involvement and ESV impacts. Furthermore, results suggested the relevance of recognizing the in-kind contributions of local businesses, which were perceived as contributing to meeting local community needs.

\section{Tracking specific barriers and hurdles}

Little is known about potential barriers and challenges to ESV. Barriers to the development of SME-nonprofit partnerships in this study were mostly related to information gaps (e.g., a lack of awareness of involvement opportunities) and a lack of understanding of the expectations and preferences of the other sector. Promoting the visibility of community initiatives and opportunities for intersectoral interactions could help address some of these partnership development challenges. The potential for negative cross-sectoral views documented by this study should be considered when aiming to support the development of intersectoral social ties. While the business case for ESV can encourage corporate community involvement, this research supplements recent study findings suggesting that overemphasizing it may deter both employees and potential community partners (Gatignon-Turnau \& Mignonac, 2015; Morgan \& Burchell, 2010; Muthuri, Matten, \& Moon, 2009). For SMEs, committing to support community needs through tangible contributions (e.g., in-kind donations, employee involvement) is more conducive to community partnerships than a focus on business outcomes.

\section{Limitations}

Study limitations include the number of participants in each respondent category and the fact that the study was conducted 


\section{Gagnon, Beaudry, Lemyre, \& Guay-Charette (2021)}

in a single location. Conducting studies in other contexts (e.g., other industries, an urban setting, Anglophone Canada) would supplement these findings. Moreover, this study focused on successful SME-nonprofit partnerships. This limits insight on the challenges faced by SMEs that are not actively involved in community engagement. Nevertheless, the diverse perspective in this study and the focus on successful SME-nonprofit partnerships resulted in a better understanding of the multi-level factors that foster ESV.

\section{Practical implications}

Results from this study suggest that in the context of SMEs and smaller (e.g., rural, semi-rural) communities, it can be more fruitful to approach ESV with a community-oriented vision focused on community development, rather than attempting to replicate formal ESV programs and procedures used by large corporations.

Since employers and employees prefer to get involved with local, familiar causes, nonprofits need to promote their organization, its activities, and local community needs beyond their target audience of beneficiaries. This can be achieved by offering public workshops or events that showcase their areas of expertise, raising public awareness about ongoing activities and initiatives (e.g., through local media outlets), participating in local business events (e.g., at the Chamber of Commerce), and organizing events for members of both sectors (fundraising events). To facilitate intersectoral understanding, nonprofit representatives should use inclusive vocabulary focusing on the joint goal of community development-rather than refer to the notion of "volunteering" when soliciting support-and formulate concrete requests for in-kind support, expertise, or skills (e.g., asking for food for an event, gift certificates for a draw, or tech support for a website). Nonprofits should also aim to explicitly express gratitude for SMEs' wide array of contributions (e.g., in-kind donations, employee volunteering, financial donations, etc.) and their outcomes at the local community level. Finally, nonprofit representatives should seek to introduce multiple members of their staff to SME representatives in order to promote the development of intersectoral ties (e.g., asking a staff member to attend a meeting, organizing a mixer with SME employees).

Having a better awareness of community initiatives (e.g., subscribing to a nonprofit's newsletter) would help local businesses stay up to date on involvement opportunities. It could also help them identify the different types of resources they could contribute to their local community (human, expertise, financial, in-kind). In order to promote better identification, assessment, and appreciation of their contribution to the community, SMEs could also create opportunities to discuss community development strategies among entrepreneurs (e.g., at the Chamber of Commerce) and with nonprofits representatives. Further, they could track estimates of in-kind contributions to community initiatives in their annual reports.

Governments could play a role in raising public awareness of how SME-nonprofit partnerships contribute to local communities. They could foster involvement by disseminating information about SME community involvement practices and their outcomes, offering tax credit incentives for different types of in-kind contributions, or matching in-kind contributions.

\section{CONCLUSION}

This study aimed to gain a better understanding of the multi-level facilitators and barriers to the development of SMEnonprofit partnerships in the context of ESV. It investigated influencing factors at the individual, organizational, and community levels as perceived by local business and community actors within a semi-rural municipality. In the context of SMEs, ESV appears to be embedded within a broad array of community-oriented business activities, rather than formally identified or implemented. The study showed that although SMEs can reap benefits when they engage in community involvement, synergistic contributions to meaningful local community outcomes contribute to the strength of SME-nonprofit partnerships. Thus, this study provides support to the social argument for SME community engagement and to reframing its role as more holistic and dynamic. 


\section{Gagnon, Beaudry, Lemyre, \& Guay-Charette (2021)}

\section{ACKNOWLEDGEMENT}

This study was conducted as part of an interdisciplinary research project entitled $\mathrm{E}=\mathrm{MC}^{2}$ (Engagement=Mobilizing Communities and Collaboration) funded by Employment and Social Development Canada (ESDC). The authors wish to thank Dr. Celine Pinsent and members of the $\mathrm{E}=\mathrm{MC}^{2}$ research team for their feedback and contributions, notably Brian Carrière for his knowledge of business social responsibility. They also wish to acknowledge the participation of the Fédération des centres d'action bénévole du Québec (FCABQ), a nonprofit representing a network of 114 volunteer centres across the province of Québec, in the development of this study, and the people from the specific community where the study took place.

\section{NOTE}

1. Names have been changed to protect confidentiality.

\section{REFERENCES}

Allen, K., Galiano, M., \& Hayes. (2011). Global companies volunteering globally: The final report of the Global Corporate Volunteering Research Project. Washington, DC: International Association for Volunteer Effort.

Amsler, L.B., \& O'Leary, R. (2017). Collaborative public management and systems thinking. International Journal of Public Sector Management, 30(6-7), 626-639.

Austin, J.E. (2000). Strategic collaborations between nonprofits and business. Nonprofit and Voluntary Sector Quarterly, 29(1_suppl), 69-97.

Austin, J.E., \& Seitanidi, M.M. (2012a). Collaborative value creation: A review of partnering between nonprofits and businesses. Part 1: Value creation spectrum and collaboration stages. Nonprofit and Voluntary Sector Quarterly, 41(5), 726-758.

Austin, J. E., \& Seitanidi, M. M. (2012b). Collaborative value creation: A review of partnering between nonprofits and businesses. Part 2: Partnership processes and outcomes. Nonprofit and Voluntary Sector Quarterly, 41(6), 929-968.

Baumann-Pauly, D., Wickert, C., Spence, L.J., \& Scherer, A.G. (2013). Organizing corporate social responsibility in small and large firms: Size matters. Journal of Business Ethics, 115(4), 693-705.

Basil, D., Runte, M., Basil, M., \& Usher, J. (2011). Company support for employee volunteerism: Does size matter? Journal of Business Research, 64(1), 61-66.

Berger, I.E., Cunningham, P.H., \& Drumwright, M.E. (2004). Social alliances: Company/nonprofit collaboration. California Management Review, 47(1), 58-90.

Boccalandro, B. (2009). Mapping success in employee volunteering: The drivers of effectiveness for employee volunteering and giving programs and Fortune 500 performance. Chestnut Hill, MA: Boston College Center for Corporate Citizenship. URL: https://www.shrm.org/hr-today/news/hr-news/Documents/MappingSucces/nEmployee Volunteering.pdf [June 15, 2020].

Bronfenbrenner, U. (1977). Towards an experimental ecology of human development. American Psychologist, 32(7), 513-531.

Caligiuri, P., Mencin, A., \& Jiang, K. (2013). Win-win-win: The influence of company-sponsored volunteerism programs on employees, NGOs and business units. Personnel Psychology, 66(4), 825-860.

Cho, M., \& Kelly, K.S. (2014). Corporate donor-charitable organization partners: A coorientation study of relationship types. Nonprofit and Voluntary Sector Quarterly, 43(4), 693-715.

Cook, J., \& Burchell, J. (2018). Bridging the gaps in employee volunteering: Why the third sector doesn't always win. Nonprofit and Voluntary Sector Quarterly, 47(1), 165-184. 


\section{Gagnon, Beaudry, Lemyre, \& Guay-Charette (2021)}

Creswell, J.W. (2007). Qualitative inquiry \& research design: Choosing among five approaches (2nd ed.). Thousand Oaks, CA: Sage Publications.

Curtis, J., Baer, D., Grabb, E., \& Perks, T. (2003). Estimation des tendances de l'engagement dans les associations volontaires au cours des dernières décennies au Québec et au Canada anglais. Sociologie et sociétés, 35(1), $115-141$.

Gagnon, M., \& Lemyre, L. (2020). Employer support for volunteering in Canada: A comparison of Francophones from Quebec and Anglophones outside Quebec based on a national survey [Unpublished manuscript]. Ottawa, ON: University of Ottawa.

Gatignon-Turnau, A.L., \& Mignonac, K. (2015). (Mis)using employee volunteering for public relations: Implications for corporate volunteers' organizational commitment. Journal of Business Research, 68(1), 7-18.

Gaudet, S., \& Reed, P. (2004). Responsabilité, don et bénévolat au cours de la vie. Lien social et Politiques, 51, 59-67. Hurst, M. (2012). Employer support of volunteering. Statistics Canada. URL: https://www150.statcan.gc.ca/n1/en/pub /11-008- x/2012001/article/11670-eng.pdf [June 15, 2020].

Hwang, M., Andersen, R., \& Grabb, E. (2007). Voluntary association activity in Quebec and English Canada: Assessing the effects of region and language. Canadian Journal of Political Science/Revue canadienne de science politique, 40(1), 209-232

Industry Canada. (2019). Principales statistiques relatives aux petites entreprises. URL: http://www.ic.gc.ca/eic/site 1061.nsf/fra/h_03090.html\#point1-1 [May 4, 2020].

Institut de la statistique du Québec. (2014). Lanaudière et ses municipalités régionales de comté (MRC), Fiche synthèse par MRC. URL: http://www.stat.gouv.qc.ca/statistiques/profils/region_14/region_14_00.htm [May 4, 2020]

Jamali, D., \& Keshishian, T. (2009). Uneasy alliances: Lessons learned from partnerships between businesses and NGOs in the context of CSR. Journal of Business Ethics, 84(2), 277-295.

Kechiche, A., \& Soparnot, R. (2012). CSR within SMEs: Literature review. International Business Research, 5(7), 97-104.

Kulik, L. (2007a). Predicting responses to volunteering among adolescents in Israel: The contribution of personal and situational variables. VOLUNTAS: International Journal of Voluntary and Nonprofit Organizations, 18(1), 35-54.

Kulik, L. (2007b). Explaining responses to volunteering: An ecological model. Nonprofit and Voluntary Sector Quarterly, 36(2), 239-255.

Laforest, R. (2011). L'étude du tiers secteur au Québec: comment saisir la spécificité québécoise? Politique et Sociétés, 30(1), 43-55.

Lorenz, C., Gentile, G.C., \& Wehner, T. (2011). How, why, and to what end? Corporate volunteering as corporate social performance. International Journal of Business Environment, 4(2), 183-205.

MacPhail, L.H., Roloff, K.S., \& Edmondson, A.C. (2009). Collaboration across knowledge boundaries within diverse teams: Reciprocal expertise affirmation as an enabling condition. In Roberts, L.M., \& Dutton, J.E. (Eds.), Exploring positive identities and organizations: Building a theoretical and research foundation (pp. 319-340). London, UK: Psychology Press.

Madden, K., Scaife, W., \& Crissman, K. (2006). How and why small to medium size enterprises (SMEs) engage with their communities: An Australian study. International Journal of Nonprofit and Voluntary Sector Marketing, 11(1), $49-60$.

Miles, M.B., Huberman, A.M., \& Saldaña, J. (2013). Qualitative data analysis. Thousand Oaks, CA: Sage Publications.

Morgan, C.W., \& Burchell, J. (2010). "It ain't wot you do, it's the way that you do it" Lessons learned from analysing employer-supported volunteering schemes through the eyes of employees. International Journal of Sociology and Social Policy, 30(11/12), 632-647.

Muthuri, J.N., Matten, D., \& Moon, J. (2009). Employee volunteering and social capital: Contributions to corporate social responsibility. British Journal of Management, 20(1), 75-89. 


\section{Gagnon, Beaudry, Lemyre, \& Guay-Charette (2021)}

Ontario (2019). Volunteering in Ontario. Toronto, ON: Government of Ontario. URL: https://www.ontario.ca/page Ivolunteering-ontario\#section-4 [June 15, 2020].

Ostrom, E. (1990). Governing the commons: The evolution of institutions for collective action. New York, NY: Cambridge University Press.

Ostrom, E. (2005). Understanding institutional diversity. Princeton, NJ: Princeton University Press.

Peloza, J., \& Hassay, D.N. (2006). Intra-organizational volunteerism: Good soldiers, good deeds and good politics. Journal of Business Ethics, 64(4), 357-379.

Putnam, R.D. (2000). Bowling alone: America's declining social capital. In Crothers, L., \& Lockhart, C. Culture and politics (pp. 223-234). New York, NY: Palgrave Macmillan.

Reed, P.B., \& Selbee, K. (2001). Formal and informal volunteering and giving: Regional and community patterns in Canada. URL: https://www3.carleton.ca/casr/Formal.pdf [May 4, 2020].

Rodell, J. (2013). Finding meaning through volunteering: Why do employees volunteer and what does it mean for their jobs? Academy of Management Journal, 56(5), 1274-1294.

Rodell, J, Breitsohl, H., Schröder, M., \& Keating, D.J. (2015). Employee volunteering: A review and framework for future research. Journal of Management, 42(1), 55-84.

Runte, M., Basil, D.Z., \& Runte, R. (2010). Corporate support for employee volunteerism within Canada: A crosscultural perspective. Journal of Nonprofit \& Public Sector Marketing, 22(4), 247-263.

Russo, A., \& Tencati, A. (2008). Formal vs. informal CSR strategies: Evidence from Italian micro, small, medium-sized, and large firms. Journal of Business Ethics, 85(2), 339-353.

Samuel, O., Wolf, P. \& Schilling, A. (2013) Corporate volunteering: Benefits and challenges for nonprofits. Nonprofit Management and Leadership, 24(2), 163-179.

Schiller, R.S., \& Almog-Bar, M. (2013). Revisiting collaborations between nonprofits and businesses: An NPO-centric view and typology. Nonprofit \& Voluntary Sector Quarterly, 42(5), 942-962.

Thomas, D.R. (2006). A general inductive approach for analyzing qualitative evaluation data. American Journal of Evaluation, 27(2), 237-246.

Turcotte, M. (2005). Social engagement and civic participation: Are rural and small town populations really at an advantage? Statistics Canada. URL: https://www150.statcan.gc.ca/n1/en/pub/21-006-x/21-006-x2005004-eng.pdf [May 4, 2020].

Turcotte, M. (2015). Spotlight on Canadians: Results from the general social survey. Statistics Canada. URL: https:// www150.statcan.gc.ca/n1/en/pub/89-652-x/89-652-x2015001-eng.pdf [May 4, 2020].

Vézina, M., \& Crompton, S. (2012). Volunteering in Canada. Statistics Canada. URL: http://www.statcan.gc.ca/pub/11008-x/2012001/article/11638-eng.pdf [May 4, 2020].

Zatepilina-Monacell, O. (2015). Small business-nonprofit collaboration: Locally owned businesses want to take their relationships with community-based NPOs to the next level. Journal of Nonprofit \& Public Sector Marketing, 27(2), 216-237.

\section{ABOUT THE AUTHORS / LES AUTEURS}

Myriam Gagnon, $\mathrm{PhD}$, is a graduate from the University of Ottawa's doctoral program in Clinical Psychology. Under the supervision of Dr. Louise Lemyre, her doctoral dissertation consisted in a multi-method analysis of the role of employersupported volunteering in local community involvement within Francophone Québec. Her research interests include community engagement and community resilience. Email: myriam.gagnon@uottawa.ca .

Myriam Beaudry, MA, is a Doctoral Candidate in Experimental Psychology at the University of Ottawa. Email: myriam .beaudry@uottawa.ca . 


\section{Gagnon, Beaudry, Lemyre, \& Guay-Charette (2021)}

Alexandra Guay-Charette, $\mathrm{PhD}$, is a graduate from the University of Ottawa's doctoral program in Political Science. She is currently a postdoctoral research fellow at the School of Community and Public Affairs at Concordia University. Email: alexandra.charette@concordia.ca .

Louise Lemyre, PhD, FRSC, is a full professor at the University of Ottawa's School of Psychology, and The R.S. McLaughlin Research Chair on Psychosocial Aspects of Population Health. Email: louise.lemyre@uottawa.ca . 